\title{
Respect Human Value to Control Software Development Failure
}

\author{
Abdul Rehman Gilal , Hafiz Ahmed Ali, Khisaluddin Shaikh, Ahmad Waqas, Rizwan Ali Abro, \\ Ruqaya Gilal
}

\begin{abstract}
People learn and define their own values to interact in different situations. It is important to know the human values (HV) for dealing humans in better ways. HV can also be helpful for software development managers to make right decisions for managing their teams well. Unfortunately, to a great extent, the very factor is ignored in software engineering (SE). This study aims to provide a basic motivation of the topic to $S E$ researchers to carry out some empirical evidences to control software development failures through respecting software developers' $\mathrm{HV}$. In order to operationalize the study, few disciplines, in which the $\mathrm{HV}$ are empirically discussed, are considered to replicate the impacts on software development. The factor $\mathrm{HVs}$ is well connected with satisfaction and improvement outcomes in sociology, education and management studies. Likewise, this study also literates the importance of $\mathrm{HVs}$ for successful software project development. This study concludes that $\mathrm{HV}$ can form strong correlations with software development roles and can be used to minimize the software failure.
\end{abstract}

Keywords: Software Engineering, Human values, software development, and Publications.

\section{INTRODUCTION}

Human is one of the complex machines and it makes hard to predict based on any specific way. Human usually prioritize the values according to the mindset. Different people keep different personalities and that led to different achievements and motivations. However, achievements and motivations are decided upon human values (H V). H.V can be defined as human's principles for guidance [1]. They are obtained on the basis of interests, adoptions, wants, wishes and the priorities and they have a great impact socially, psychologically, anthropologically which are almost present in every discipline. Understanding H.V is a non-terminating process [2]. A "Value Theory" was proposed by Schwartz based on universal types of H.V viewing on the basis of

Revised Manuscript Received on December 30, 2019.

* Correspondence Author

Abdul Rehman Gilal , Faculty, Computer Science department, Sukkur IBA University, Pakistan

Hafiz Ahmed Ali, IT Assistant, Benazir Bhutto Shaheed University

Khisal ud din Shaikh, Technology and Skill Development

Khisal ud din Shaikh, BS Computer Science (Shah Abdul Latif University Khairpur)

Ahmad Waqas, Ph.D. at International Islamic University Malaysia

Rizwan Ali Abro, ABET Coordinator, Department of Computer Science, Sukkur IBA University.

Ruqaya Gilal, PhD student, University Utara Malaysia.

(C) The Authors. Published by Blue Eyes Intelligence Engineering and Sciences Publication (BEIESP). This is an open access article under the CC BY-NC-ND license (http://creativecommons.org/licenses/by-nc-nd/4.0/) presentation according to the Human values are used to describe societal gatherings, social orders and people to follow change after sometime and also to clarify the

inspirational bases of attitudes and conduct of people. Schwartz proposed that many theories are agreed on the following main features of values that are (i) believing, (ii) taking to desirable goals, (iii) varying according to activities and circumstances, (iv) generating principles and criteria, (v) helping in selection and (vi) the evaluation of activities, rules, events and policies. H.V are prioritized by their importance over another value according to people. These six features are common to all values. [3]. The value theory gave ten basic values (i.e. Self-Direction, Stimulation, Power, Security, Achievement, Conformity, Hedonism, Tradition, Universalism and Benevolence) in terms of motivation that is under all of the values. These values can be interpreted universally because all of them are hidden in three main universal human requirements: biological, interactional and social demands for socially welfare groups. The theory told that people represent these requirement either collectively or individually in a cognitive way for a specific value and interact with each other to achieve a goal [4].Human is the most important creature of the world. Every person has different way of perceiving the world that differentiate demographically and culturally on the basis of norms and values. H.V are very important at various stages of human's life. Human come across different stages i.e. education and career but every stage human has to deal socially. H.V are desirables and change according to the goals with different situations [5]. H.V are the integral part of the human nature because values are the conceptual believes serve different functions and purposes [6]. H.V keep intellectuality-based structure that operates as a central aspect of one 'self, can be understand with the perception, attitude, goals and behavior. $\mathrm{H} . \mathrm{V}$ are important to understand as Maio came up with the conclusion after asking the people about their values, people are unable to tell the explicit importance of values to them [7].H.V has great impact and significance in the social sciences. H.V may describe the ideas and thoughts also the behavior at individual as well as at aggregate level [8]. As human is lacking in understanding and defining human values for himself or herself while researchers have different views in different fields. Human plays a vital role towards the effectiveness and survival of an organization. Taking into account, it is an employee who decides the customers' feedback and views about the quality of services for what they are paying. Human resource managers should consider why and how the employees feel [9]. They must understand employer values according to their priorities.

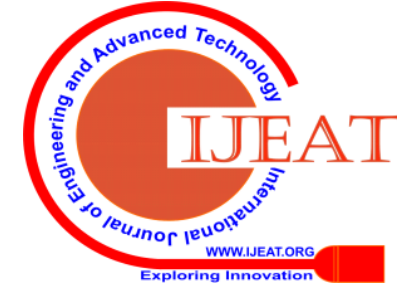


The management can reorient the performance and practices of workers if it leads towards the better services to customers. Similarly, in the selection process of employee in tourism: personality of employee has been gaining importance by recent time. Personality has direct influence of employee performance[9]. Human values are appeared in few studies among different domains. Currently H.V is an emerging research area to study human capacitates in a better way. Sandhya said that an intelligent manager would always try to retain the employee. One of the strategy is to motivate them that can boost the employee to work in the organization [10]-[13]. All the H.V are for the achievement of motivational goals [3]. There are many research domains where human values are in consideration, For example, one of the goals of self-direction is creativity that is limited by assigning repetitive and boring task again and again in hospitality sector [14]. Similarly, education is baseless if there is no integration of $\mathrm{H} . \mathrm{V}$ in students from their very basic level of education. Educational Institutions kept a crucial importance in developing the personality and professional identity of students. However, personality is based on attitude, mindset and human values. Liisa Myyry found that with education a significance gain is there in moral development in universalism and hedonism as well as a significance change in moral reasoning and stimulation of the students [15]. With different examples in other domains it is considered that researchers are talking about H.V to improve the quality of life however in Software engineering (S.E) it is being neglected. According to Parera in S.E we are fail to account the human values [12], [16]-[20]. The consequences are in the form of dissatisfaction of user and impact badly on software industry. It is a public demand now that system should consider H.V on priority in S.E. Therefore, to make S.E better and reduce failure; it is necessary to understand the human values.

\section{RELATED WORK}

Human values guide individuals to consider the human element when one collaborates with one another. They have numerous constructive characters that make obligations of mankind among individuals and along these lines have an incentive for every single person. Inside society for any pragmatic life H.V have a great impact and it use to create space for movement towards each other which prompts harmony. Even H.V are shared by every single individual nonetheless their religion, nationality and the way of life. Schwartz summarized these ten universal values in four further value dimensions: Self-Transcendence known as first quadrant while Self-Enhancement and Openness to change are said to be second and third quadrant respectively. Conversation known as fourth quadrant. Values are placed in these quadrants on the basis of their motivational goals. Formation of these values give us two bipolar dimensions those of individualism-collectivism and change-continuity dimensions [21]. The nature of values comes in Universalism and Benevolence are motivationally same. I.e. peace, harmony and wisdom in universalism and helpfulness, loyalty and spirituality are under the umbrella of benevolence. This nature makes them to come in the Self-Transcendence quadrant of Schwartz value dimensions. Hence, self-transcendence sets up a more prominent worry for the prosperity of others[22].Conservation arranges individuals to ensure and keep up what they have now, such as request, self-guideline, and protection from change. Moreover, conformity means obedient, self-discipline and politeness in nature. Tradition also having humbleness and respect matching with the goal of Conformity. Social order, healthy and sense of belonging can be found in the Security value. Schwartz placed them in Conservation quadrant [22]. The third quadrant of the value dimensions is Self-Enhancement. Self-Enhancement makes people to think of themselves and to maintain their self-esteem. Hence, self-enhancement builds up the specific interests of an individual and the improvement of one's maximum capacity. Power, Achievement and Hedonism values can be found in this quadrant because social recognition, self-respect pleasure goal respectively. Hedonism is a value that does not fit into one quadrant. The nature of enjoying life and trying new things put hedonism into the Openness to change quadrant. Openness to change inspires activities, self-governed thinking and new experiences. For instance, self-direction having creativity and freedom goals while stimulation has goals to take risks and exciting life. The nature of these elements comes in the Openness to change quadrant [22]

Table 1. The model of Schwartz [1] based on ten basic human values and their goals

\begin{tabular}{|l|l|}
\hline Values & Goals \\
\hline Self - Direction & Individual thinking and self-choosing, creating, discovering. \\
\hline Stimulation & Enthusiasm, innovation, dare. \\
\hline Hedonism & Joy or arousing satisfaction for oneself. \\
\hline Achievement & Success after proving oneself according to the social standards. \\
\hline Power & Status and respect, Dictation over people and resources. \\
\hline Security & $\begin{array}{l}\text { Security, coordination, and steadiness of society, of relationships, } \\
\text { and of self. }\end{array}$ \\
\hline Conformity & Limit of desires likely to upset others and violate social norms. \\
\hline Tradition & $\begin{array}{l}\text { Admiration, and acceptance of ideas that a culture or religion } \\
\text { possessed. }\end{array}$ \\
\hline Benevolence & $\begin{array}{l}\text { Protecting the welfare of those with whom one is in frequently in } \\
\text { touch, (groups). }\end{array}$ \\
\hline Universalism & $\begin{array}{l}\text { Considering, tolerance, and protection for the welfare of everyone } \\
\text { and for environment. }\end{array}$ \\
\hline
\end{tabular}

Generally, there are several models for measuring the human values from different aspects. Short Schwartz Value Survey (SSVS) tool is used most commonly. Marjaana Lindeman showed reliability and validity of the SSVS after examination and also to which extant the results are co-relating with the help of portrait questioner model (PVQ) scale. A rating tool to accomplish the SSVS. PVQ was obtained by Schwartz to enable the people with having less thinking ability, from less developed areas, young, elders or people from less developed areas [23]. Schwartz gave 57 items and 10 values scales. The scales with the value items in parentheses are: Self-Direction (creativeness, liberty, inquisitiveness, freedom, setting goal by oneself), Stimulation (bold, diverse and inspiring life,

exciting life), Conformity (respect, to honor the elders and parents, self-organized, graciousness), Hedonism (fulfilment of needs, pleasure in one's life, luxury), Power (social power, controlling over things, prosperity), Achievement (accomplishment, ability, determination, inspiration for individuals and actions),

Published By:

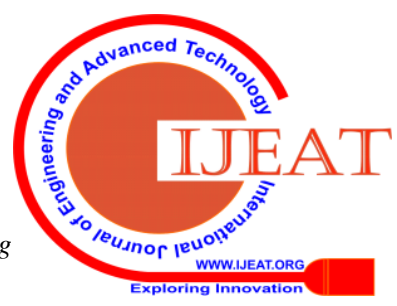


Universalism ( beauty of nature and arts, tolerance, a world at peace, fairness, social justice, knowledge, environmental safety, world at peace), Tradition (modesty, honor the tradition, accepting one's share in life,

self-effacement, devotion), Benevolence (trustworthiness, tolerance, helpfulness, devotion, duty), and Security (family security, national security, social order, reciprocation of favors, cleanliness). Scores on these 10 value scales are showed in two dimensions: Self-Enhancement versus Self-Transcendence and Openness to Change versus Conservation [5]. The participants in the study were asked to rate the values on a 9-point scale significant for them as their life-guide principles. The range of scale is defined as -1 (opposing my principles), 0 (not important), 3 (important), to 7 (most importance). After acquiring the results, the scores were obtained using the formula: i.e. the score of value Power were obtained as follows: Power $=($ social power + wealth + authority $) /(3 \times$ personal mean of all items. Same is applied for each of the 10 scales. Dividing the sum of the appropriate items by the personal mean of all items multiplied by the number of items on the scale. Marjaana used Kruskal,Young, Shepard, and Torgerson [24] KYST tool to make a multidimensional representation of the correlation among ten values. Distance among the points gave an empirical relationship between the values [23]. Finally, the proved that the new scale or SSVS is reliable and validate.

\section{METHODOLOGY}

This study motivates researchers to control the software development failures based on the empirical evidences by keeping in view the software developers' human values that may be alarming factor if ignored. It can help software engineering (SE) organizations to realize and improve the situations suitable based on the human related norms. This study is among the few studies that have focused the human values (HV) in SE. Therefore, to generate the pace, few HV research areas are selected for reviews and recommendations: sociology, education and the business. These are selected in order to setup the standard lines for researchers who are interested to contribute in the very area. The areas of study are found very useful in carrying out the desired results. It is also found that these domains are corelating with SE as they deal with the human and its emotions. This study may also aim in the future to test the comparability of human across the countries and measure the human values in different cultures. In this study, in order to extract the information from the selected articles, population is counted for proposing the suitable size for future studies. Not only the number of the participant but also the type of participant is important for effective experimental design. Hence, professional and students are extracted separately to see if there are any experience-based differences in HVs. Moreover, gender and age variables are also observed in order to see if there is any studies that are explicitly segregating the gender and age based HVs. Lastly, measuring the HVs through a proper tool is also an important job. Therefore, this study also looks for the tools used for extracting HVs.

\section{RESULTS \& EXPERIMENTAL SETUPS IN THE HV STUDIES}

This part of the study, presents the experimental details that are basically carried out by authors in different domains. As in sociology, Education, Business and finally S.E. A detailed discussion is done upon the domains. The importance of H.V and their empirically measurement. The reason of comparing different domains is to take the attentions of practitioners related with software development to Human values at every stage of software development.

a) Sociology

Values are important part of culture [25], [26]. The role of value in social science is discussed on both individual and aggregate levels. Values may explain individual's attitude and opinion about societal groups and politics. Also, they may relate to see reflect on societal change and impact its rate of change in aggregate level. However, the differences in governmental policies in several countries may also be relate in aggregate level of values. Culture is defined as "a system of attitudes, values and knowledge that is widely shared within a society and transmitted from generation to generation". When societal conditions changes they may influence culture towards change [25]. Eldad Davidson [27] conducted the study to check the comparability and compatibility of human values. From the European Social Survey (ESS), the study measures the 10 values from Values Theory proposed by Schwartz in 25 countries [5]. It is also highlighted that how avoiding non-invariance can be a major issue to compare values across countries. Multi-group Confirmatory Factor Analysis (MGCFA) used to assess the comparability of values across different countries. Test carried out by Eldad of values from (2002-07) suggested that the measurements of values by ESS are not appropriate for accounting 10 values. Furthermore, some of values are combined. The study also disclose that the invariance of six values found in 21 countries that suggested that these values may have same meaning because of their correlation[27]. In a single country's investigations, somewhere in the range of four and seven qualities could be recognized in every country. Moreover, issues of the need to bind together qualities or presenting cross-loadings were exhibited. In last, this study also discussed the problems which were coming across during the analysis face of invariance. The following Table 2 presents the methods, tools and domains in which consideration on H.V is increasing in sociology the study is on international level that authors have compared the H.V among different countries.

\section{b) Education}

The study is based on Schwartz model to asses that either the value preference in the variation during the higher education and also which values dominates to develop student moral values. The experiment was divided in two times. In time 1, 599 participants were chosen. The percentage of females having mean age of 23.6 years is $76 \%$.

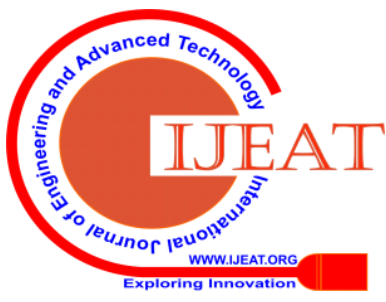


Table 2. Detail description of experimental setups in $\mathrm{HV}$ studies

\begin{tabular}{|c|c|c|c|c|}
\hline Area & $\begin{array}{c}\text { Sociology } \\
\text { [19] }\end{array}$ & $\begin{array}{c}\text { Education } \\
\text { [12] }\end{array}$ & $\begin{array}{c}\text { Business } \\
\text { [14] }\end{array}$ & $\begin{array}{l}\text { S.E } \\
{[20]}\end{array}$ \\
\hline Project & $\begin{array}{l}\text { Comparabilit } \\
\text { y of Human } \\
\text { Values tested } \\
\text { across the } \\
\text { countries. }\end{array}$ & $\begin{array}{l}\text { Change in } \\
\text { values and } \\
\text { moral } \\
\text { reasoning } \\
\text { during higher } \\
\text { education. }\end{array}$ & $\begin{array}{l}\text { Responsibilit } \\
\text { y of } \\
\text { employee } \\
\text { and their } \\
\text { basic Human } \\
\text { Values in } \\
\text { hospitality } \\
\text { sector. }\end{array}$ & $\begin{array}{l}\text { Measuring } \\
\text { Human Values } \\
\text { in S.E }\end{array}$ \\
\hline Objective & $\begin{array}{l}\text { Measure the } \\
\text { H.V across } \\
\text { different } \\
\text { cultures. (25 } \\
\text { Countries) }\end{array}$ & $\begin{array}{l}\text { Does } \\
\text { Schwartz } \\
\text { Human } \\
\text { Values bring } \\
\text { any change in } \\
\text { higher } \\
\text { education } \\
\text { during the } \\
\text { studies? }\end{array}$ & $\begin{array}{l}\text { To } \\
\text { investigate } \\
\text { the } \\
\text { connection } \\
\text { between the } \\
\text { personal } \\
\text { values of } \\
\text { different } \\
\text { groups of } \\
\text { hospitality } \\
\text { sector. } \\
\end{array}$ & $\begin{array}{l}\text { Empirical } \\
\text { examination of } \\
\text { Human Values, } \\
\text { also to get clear } \\
\text { scientific } \\
\text { understanding in } \\
\text { software } \\
\text { engineering }\end{array}$ \\
\hline Population & 47099 & 132 & 352 & 12 \\
\hline Gender & Male & $80 \%$ females & $\begin{array}{l}58.8 \% \\
\text { females \& } \\
41.2 \% \text { males } \\
\end{array}$ & Both \\
\hline Age & N/A & $\begin{array}{l}\mathrm{T} 123.6, \mathrm{~T} 2= \\
26.4 \text { (years) }\end{array}$ & $\begin{array}{l}39.5 \text { years } \\
\text { (average) }\end{array}$ & N/A \\
\hline Country & Europe & Finland & Europe & NA \\
\hline $\begin{array}{c}\text { Professional/ } \\
\text { student }\end{array}$ & Professional & Student & Professionals & Professional \\
\hline Tool & PVQ & $\begin{array}{l}\text { SSVS with } \\
\text { PVQ }\end{array}$ & PVQ & Q-Sort \\
\hline Conclusion & $\begin{array}{l}\text { It is observed } \\
\text { that the in } \\
\text { variance of } \\
\text { self-enhance } \\
\text { ment and } \\
\text { openness to } \\
\text { change were } \\
\text { the } \\
\text { established } \\
\text { around all the } \\
\text { countries on } \\
\text { ESS rounds. }\end{array}$ & $\begin{array}{l}\text { To inspect } \\
\text { the student at } \\
\text { the time of } \\
\text { entering in } \\
\text { higher studies } \\
\text { and leaving } \\
\text { the institute } \\
\text { the changes } \\
\text { in values and } \\
\text { moral } \\
\text { development. }\end{array}$ & $\begin{array}{l}\text { Observed the } \\
\text { personal } \\
\text { values of } \\
\text { employees } \\
\text { and their } \\
\text { professional } \\
\text { profiles in the } \\
\text { hospitality } \\
\text { sector. }\end{array}$ & $\begin{array}{l}\text { Three } \\
\text { prototypes (L1, } \\
\text { L2 and L3) of } \\
\text { software } \\
\text { engineers with } \\
\text { their structure } \\
\text { have been } \\
\text { described. } \\
\text { Quantitative } \\
\text { analysis is } \\
\text { generate4d } \\
\text { using the value } \\
\text { Q-Sort tool. All } \\
\text { three prototypes } \\
\text { maybe used to } \\
\text { determine the } \\
\text { Human Values } \\
\text { in Software } \\
\text { engineering }\end{array}$ \\
\hline
\end{tabular}

Whereas, there is a difference of almost 3 years in Time 1 and Time 2. Time 2 experiment was based on 132 of the original participants $80 \%$ females having 26.4 years mean age. Also, there were $80 \%$ females having the mean age of 23.6 years. So only 132 were again gave the attempt so the values are according to 132 participants. The respondent were asked to judge similarities by comparing the portrait to themselves with the help of PVQ rater having 6-points (1= not like men at all: $6=$ Very much like me). On the basis of 40 different people. [29]. The value types include six items. At T1, the alphas varies from .43 to .87 while .44 to .86 at T2. The combined sum variables were used in the study to control over the variance use of the scale. At first, mean of all the 40 individuals were calculated for each participant independently, than the sum variable was divided by the individual means [15]. The motivation behind this examination was to explore values transformation and moral development in higher education and in their friends. The actual intrigue was to inspect whether or not the individual worth needs at understudies time entering school, anticipate gain of moral development. Also, to discover whether the change in moral development and in values exists at the same time.

\section{c) Business}

We found that there are different domains concerning about the human values. Researchers of respective domain taking attentions to the importance of human values. Similarly, business is also a domain which can't be ignored. Human values keep importance in developing the character of a person. People linked with an organization priority their tasks according to their mindset. In hospitality sector Antonio Examined the interconnection of the personal values of diverse groups in hospitality sector. In the study, a sample of 352 professionals from the hospitality sector was taken including International Standard Classification of Occupations 2008. The sample distribute on the basis of four different groups/categories: Restaurant Managers, Cooks and Chefs, Bartenders and Waiters and Kitchen Helpers. All groups comprise of 88 individuals. Moreover, total sample was based on $58.8 \%$ of women and $41.2 \%$ of men. The average age of each individual was 39.5 years. The study was based on Schwartz Value theory and the rating for values according to each individual was overall sample included the following initial rates: benevolence (5.10), self-direction (4.85), universalism (4.82), security (4.78) and tradition (4.38).

The basic objective was to determine whether the profile varied among diverse occupations of the restaurant sector. The values found most important for restaurant managers were benevolence (5.14), self-direction (5.13), universalism (5.00), security (4.79) and achievement (4.61). The priority values for cooks and chefs were arranged as follows: benevolence (4.99), security (4.86), self-direction (4.76), universalism (4.60) and achievement (4.45). The profile for the European waiters: benevolence (5.06), self-direction (4.89), universalism (4.79), hedonism (4.64), and security (4.63). Definition of Kitchen Helpers is based on benevolence (5.21), universalism (4.92), security (4.84), self-direction (4.61) and tradition (4.38). After using the Schwartz Method PVQ like other studies Antonio concluded that statistically significant difference is there among managers and other occupations. Through whole discussion of the study Chi-square test: 118.58: Sig. 0.000)[21].

\section{d) Software Engineering}

Keeping in view the importance of human values in every domain. Winter carried out a study to highlight the impact of human values in SE [30]. Their study findings focused two principles: values are distinguishing from ethics and there should be a robust theoretical framework to understand human values. Winter, referred

Maio framework of three interconnected levels as the starting point of their research to investigate value in systematic way[31]. This framework deliberates values in mental representation. Comprises of: (L1) the universal or system level, (L2) abstract or personal level and (L3) instantiation level. For measuring values in SE and stimulate values plots on three levels, Q-Sort tool were used. 
The Q-sort is mixed method tool has been developed by William Stephenson in 1930 [32].Q-sort method resembles closely with three level framework [33]. The Q-sort involves the participants by asking series of statements and allow those to rank based on their level of agreement to particular statement (L1). Interviews also were conducted from the participants to understand how they perceived those values (L2). And to get closer view of (L3), participants were asked to fill in the Q-sort tool for each specific product on which they were working. To investigate the human subjectivity, the Q-sort tool perceived as the strong tool. because it produces results that are statistically valid with small samples [34].

Furthermore, Q-sort statements were also being formulated into framework by using Schwartz's values types. The Q-sort designed significantly for software professionals by making statements more clear rather than using technical language [35]. For each value, statements of Q-Sort are based on the code of ethics principles. The Q-Sort statement document has been distributed among the 12 software professionals from different level of expertise and different sectors. [28]. Interviews also conducted by these 12 software practitioners. Followed by asking their role, current project and career path so that they are invited to fill in the Q-sort questioner for their particular project. The length of interviews varies form 45 minutes to 90 minutes. After this exercise, the data taken from the participants through Q-sort data was analyzed through Q-analysis program. This analysis accomplishes factor analysis to identify the similarity patterns in the Q-sort configurations [36]. Eight different factors were found from the centroid factor analysis [28]Out of these 8 three factors having eigenvalues greater than 1 were selected for further analysis process. Data analyzed by the using Varimax rotation to cover maximum amount of variance [36]. Each of the factor seen as viewpoint and can be considered as prototype: The Autonomous, Nonconforming Risk-taker, The Intrinsically-driven and The Fun-loving, Extrinsically-driven Software Engineer. These three considered as software engineer prototypes were introduced as result. Such prototypes can be used for systematic reasoning of values in SE [28].

\section{CONCLUSION}

Several studies in the literature have given acute importance to human values (HV) but software engineering (SE). This statement is made after the SE literature comparison with Business, Education and Sociology literatures where HVs are explicitly explored. It is a discussed fact that ignorance of HVs can cause the software projects failure. Moreover, based on the limited survey of this study, it is suggested that every software development role invokes different physical and mental situations. Therefore, it is recommended that one should consider different software development roles to identify the accurate and suitable HVs pertain to nature of job. For instance, requirement engineer has to have Self Direction, Stimulation and Hedonism values in him. Additionally, one must not ignore the gender-based division of HVs during exploring the values for particular job. It is said because male developers can never demand and prioritize the things as female developers. Similarly, ethnographical values should also be considered for further intense results. This study had found that both students and professionals are considered in the past for experimental results. Hence, it is also recommended that based on the professional values academic institutes should reform their policies for producing professionally desired values. In other words, experimental studies should be conducted on the professionals to guide the academia to induce required HVs for future software developers by providing them environment. Lastly, this study is not free from limitations but this study is presented to derive the focus of researchers on this topic.

\section{REFERENCES}

1. S. H. Schwartz and W. Bilsky, "Toward a universal psychological structure of human values.," J. Pers. Soc. Psychol., vol. 53, no. 3, p. 550, 1987.

2. M. Rokeach, The nature of human values. Free press, 1973

3. S. H. Schwartz, "Basic human values: Theory, methods, and application," Risorsa Uomo, 2007.

4. S. H. Schwartz and K. Boehnke, "Evaluating the structure of human values with confirmatory factor analysis," J. Res. Pers., vol. 38, no. 3, pp. 230-255, 2004.

5. S. H. Schwartz, "Universals in the content and structure of values: Theoretical advances and empirical tests in 20 countries," in Advances in experimental social psychology, vol. 25, Elsevier, 1992, pp. 1-65.

6. P. G. Bain, Y. Kashima, and N. Haslam, "Conceptual beliefs about human values and their implications: Human nature beliefs predict value importance, value trade-offs, and responses to value-laden rhetoric.,"J. Pers. Soc. Psychol., vol. 91, no. 2, p. 351, 2006.

7. M. M. Bernard, G. R. Maio, and J. M. Olson, "Effects of introspection about reasons for values: Extending research on values-as-truisms," Soc. Cogn., vol. 21, no. 1, pp. 1-25, 2003.

8. E. Davidov, "A cross-country and cross-time comparison of the human values measurements with the second round of the European Social Survey," in Survey Research Methods, 2008, vol. 2, no. 1, pp. 33-46.

9. S. Kusluvan, Z. Kusluvan, I. Ilhan, and L. Buyruk, "The human dimension: A review of human resources management issues in the tourism and hospitality industry," Cornell Hosp. Q., vol. 51, no. 2, pp. 171-214, 2010.

10. K. Sandhya and D. P. Kumar, "Employee retention by motivation," Indian J. Sci. Technol., vol. 4, no. 12, pp. 1778-1782, 2011.

11. A. R. Gilal, M. Omar, and K. I. Sharif, "A RULE-BASED APPROACH FOR DISCOVERING EFFECTIVE SOFTWARE TEAM COMPOSITION," JICT, pp. 1-20, 2014

12. A. R. Gilal, M. Omar, and K. I. Sharif, "DISCOVERING PERSONALITY TYPES AND DIVERSITY BASED ON SOFTWARE TEAM ROLES," in International Conference on Computing and Informatics, ICOCI 2013, 2013, pp. 259-264.

13. A. R. Gilal, J. Jaafar, S. Basri, M. Omar, and A. Abro, "Impact of software team composition methodology on the personality preferences of Malaysian students," in 2016 3rd International Conference on Computer and Information Sciences, ICCOINS 2016 Proceedings, 2016.

14. I. Dienstbühl et al., Protecting workers in hotels, restaurants and catering. Office for Official Publications of the European Communities, 2008.

15. L. Myyry, S. Juujärvi, and K. Pesso, "Change in values and moral reasoning during higher education,” Eur. J. Dev. Psychol., vol. 10, no. 2, pp. 269-284, 2013.

16. H. Perera et al., "A Study on the Prevalence of Human Values in Software Engineering Publications, 2015-2018,” arXiv Prepr. arXiv1907.07874, 2019.

17. A. R. Gilal, J. Jaafar, M. Omar, S. Basri, and I. A. Aziz, "Balancing the personality of programmer: Software development team composition,' Malaysian J. Comput. Sci., vol. 29, no. 2, 2016.

18. M. Z. Tunio et al., "Impact of Personality on Task Selection in Crowdsourcing Software Development: A Sorting Approach," IEEE Access, 2017. 
19. J. Jaafar, A. R. Gilal, M. Omar, S. Basri, I. Abdul Aziz, and M. H. Hasan, "A Rough-Fuzzy Inference System for Selecting Team Leader for Software Development Teams," in Advances in Intelligent Systems and Computing, vol. 661, Springer, Cham, 2017, pp. 304-314.

20. A. R. Gilal, J. Jaafar, S. Basri, M. Omar, and M. Z. Tunio, "Making Programmer Suitable for Team-Leader: Software Team Composition Based on Personality Types," in International Symposium on Mathematical Sciences \& Computing Research (iSMSC) 2015 (iSMSC' 15), 2015.

21. A. Ariza-Montes, J. M. Arjona-Fuentes, H. Han, and R. Law, "Employee responsibility and basic human values in the hospitality sector,” Int. J. Hosp. Manag., vol. 62, pp. 78-87, 2017.

22. S. H. Schwartz, "Are there universal aspects in the structure and contents of human values?” J. Soc. Issues, vol. 50, no. 4, pp. 19-45, 1994.

23. M. Lindeman and M. Verkasalo, "Measuring values with the short Schwartz's value survey," J. Pers. Assess., vol. 85, no. 2, pp. 170-178, 2005.

24. J. B. Kruskal, F. W. Young, and J. B. Seery, "How to Use Kyst - A Very Flexible Program to Do Multidimensional Scaling and Unfolding." 1977.

25. R. Inglehart, Culture shift in advanced industrial society. Princeton University Press, 2018.

26. A. R. Gilal, J. Jaafar, M. Omar, S. Basri, and A. Waqas, "A Rule-Based Model for Software Development Team Composition: Team Leader Role with Personality Types and Gender Classification," Inf. Softw. Technol., vol. 74, pp. 105-113, 2016.

27. E. Davidov, "Testing for comparability of human values across countries and time with the third round of the European Socia Survey," Int. J. Comp. Sociol., vol. 51, no. 3, pp. 171-191, 2010.

28. E. Winter, S. Forshaw, and M. A. Ferrario, "Measuring human values in software engineering," in Proceedings of the 12th ACM/IEEE International Symposium on Empirical Software Engineering and Measurement, 2018, p. 48

29. S. H. Schwartz, A. Lehmann, and S. Roccas, "Multimethod probes of basic human values," Soc. Psychol. Cult. Context Essays Honor Harry C. Triandis, pp. 107-123, 1999.

30. E. Winter, S. Forshaw, L. Hunt, and M. A. Ferrario, "Advancing the study of human values in software engineering," in Proceedings of the 12th International Workshop on Cooperative and Human Aspects of Software Engineering, 2019, pp. 19-26.

31. G. R. Maio, "Mental representations of social values," in Advances in experimental social psychology, vol. 42, Elsevier, 2010, pp. 1-43.

32. W. Stephenson, "Introduction to Q-methodology," Operant Subj., vol. 17, no. 1, pp. 1-13, 1993.

33. G. R. Maio and J. M. Olson, "Values as truisms: Evidence and implications.," J. Pers. Soc. Psychol., vol. 74, no. 2, p. 294, 1998.

34. M. P. Davoren, M. Cronin, I. J. Perry, and K. O'Connor, "Alcohol consumption among university students: a typology of consumption to aid the tailoring of effective public health policy," BMJ Open, vol. 6, no. 11, p. e011815, 2016.

35. K. W. Miller and D. K. Larson, "Agile software development: human values and culture," IEEE Technol. Soc. Mag., vol. 24, no. 4, pp. 36-42, 2005.

36. S. Watts and P. Stenner, Doing Q methodological research: Theory, method \& interpretation. Sage, 2012.

\section{AUTHORS PROFILE}

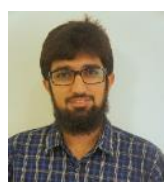

Abdul Rehman Gilal is a faculty member of Computer Science department at Sukkur IBA University, Pakistan. He has earned Doctor of Philosophy (Ph.D.) in Information Technology from Universiti Teknologi Petronas (UTP), Malaysia. He has been mainly researching in the field of software project management for finding the effective methods of composing software development teams. Based on his research publication track record, he has contributed in the areas of human factor in software development, complex networks, databases and data mining, programming and cloud computing.

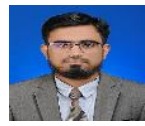

Hafiz Ahmed Ali BS Computer Science (Shah Abdul Latif University Khairpur).

Scholar at Computer Science Department enrolled in MS Computer Science (Sukkur IBA University). IT Assistant at The Benazir Bhutto Shaheed University of Technology and Skill Development

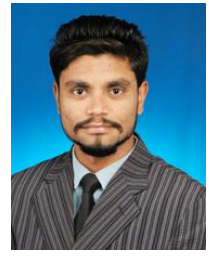

Khisal ud din Shaikh BS Computer Science (Shah Abdul Latif University Khairpur). Scholar at Computer Science Department enrolled in MS Software Engineering (Sukkur IBA University). ICT Teacher at The City School,Indus Campus Sukkur.

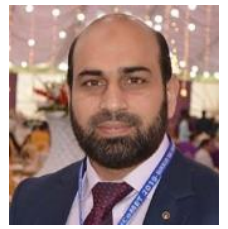

Ahmad Waqas is an Associate Professor in the Department of Computer Science. He Completed his Ph.D. at International Islamic University Malaysia. His teaching and research interests include Distributed Systems, Cloud Computing, Network Design, Security and Management, Algorithms and Data Structures and Theoretical computer science. Dr. Ahmad Waqas has published numerous research articles in renowned journals and conferences proceedings including WOS, Scopus, and IEEE. He is the Chief Editor of Sukkur IBA Journal of Computing and Mathematical Sciences (SJCMS). He also organized the 2017 International Conference on Computing and Mathematical Sciences and served as General Co-Chair. He has been serving as Editorial Board Member, Program Committee Member and Technical Program Committee Member of many journals and international conferences.

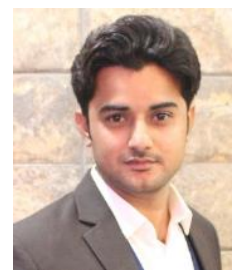

Rizwan Ali Abro received his Bachelor degree in Computer Science in 2015 from Sir Syed University of Engineering \& Technology and Master's degree specialized in Data Knowledge Engineering in 2019 from Sukkur IBA University. During the Master's Degree he got opportunity to work as a Research Assistant in the Department of Computer Science Sukkur IBA University, where he assisted in the many research projects. Currently he is working as ABET Coordinator in the Department of Computer Science, Sukkur IBA University.

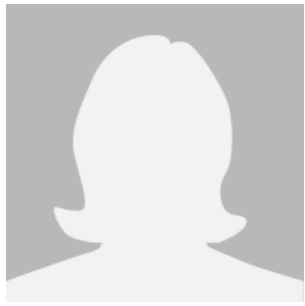

Ruqaya Gilal is a $\mathrm{PhD}$ student in Universiti Utara Malaysia. Her areas of specialization are software engineering, data mining and human psychology. 